\title{
BICENTRIC BIPOLAR PROSTHESIS IN NON-TRAUMATIC HIP PATHOLOGIES: MAXIMUM 10 YEARS FOLLOW UP
}

\author{
Jha SC ${ }^{1}$, Rai $A K^{2}$, Shakya $P^{3}$
}

\section{Affiliation}

1. Department of Orthopedics, Birat medical college and Teaching Hospital, Biratnagar, Nepal

2. Department of Orthopedics, Institute of Medical Science, Banaras Hindu University, India

3. Graduate School of Medicine, University of Tokyo, Tokyo, Japan

\section{ARTICLE INFO}

\section{Article History}

Received : 04 June, 2017

Accepted : 20 July, 2017

Published : 31 December, 2017

(C) Authors retain copyright and grant the journal right of first publication with the work simultaneously licensed under Creative Commons Attribution License CC - BY 4.0 that allows others to share the work with an acknowledgment of the work's authorship and initial publication in this journal.

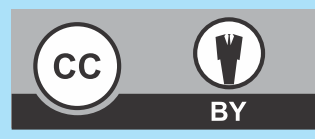

\section{ORA 36}

DOI: $\underline{\text { http://dx.doi.org/10.3126/bjhs.v2i3.18934 }}$

\section{* Corresponding Author \\ Dr. Subash Chandra Jha \\ Assistant Professor \\ Department of Orthopedics}

Birat Medical College and Teaching Hospital

Tankisinwari, Biratnagar, Nepal

E-mail : subash.jha@gmalil.com

\section{Citation}

Jha SC, Rai AK, Shakya P. Bicentric Bipolar Prosthesis in Non-traumatic Hip Pathologies: Maximum 10 Years Follow Up. BJHS 2017;2(3)4 :238-243

\section{ABSTRACT}

\section{Introduction}

Introduction of bipolar prosthesis was basically made for the treatment of fresh fracture neck of femur in elderly, but with advancement in design and techniques its use has been increased to various non-traumatic hip pathologies.

\section{Objective}

To assess clinical and radiological outcome of BHU bicentric bipolar hip prosthesis in treatment of non-traumatic hip pathology.

\section{Methodology}

This longitudinal study was done in 30 cases of various hip conditions, during the period of March 2002 to March 2012. All patients had secondary osteoarthritis of hip with abnormal acetabulum following advanced tubercular arthritis, rheumatoid arthritis, ankylosing spondylitis and avascular necrosis of femoral head. Primary bipolar hemi-replacement arthroplasty was done in all the cases using Banaras Hindu University (BHU) bicentric bipolar hip prosthesis. Each patient was assessed radiologically for movement and fraction of it occurring at various components of prosthesis and clinically for functional outcome using modified Harris hip score for the maximum of 10 years.

\section{Results}

There were 17 males and 13 females $(n=30)$, aged between $31-60$ years. Three and half years following surgery, $(n=12)$ $100 \%$ patients were able to squat and sit crossed legged. At four and half years follow-up, $(n=7) 100 \%$ patient had excellent result when assessed by modified Harris hip score. Radiologically, by the end of 10 years $(n=1)$ all the movements of hip occurred at inner bearing while the outer bearing was fixed to acetabulum.

\section{Conclusion}

This intermediate term follow-up study suggests that the use of BHU bicentric bipolar hip prosthesis for bipolar hemireplacement is associated with better clinical outcomes, in non-traumatic hip pathologies.

\section{KEYWORDS}

BHU bicentric bipolar hip prosthesis, follow up, secondary osteoarthritis 


\section{INTRODUCTION}

Bateman and Giliberty introduced bipolar implant for hip reconstruction, principally in fracture neck of femur, avascular necrosis of femoral head and non-union of femoral neck in an attempt to alleviate the problems of conventional metallic proximal femoral endoprosthesis. ${ }^{1,2}$ The bipolar hip prosthesis has a ball and joint socket, and the majority of motion is supposed to occur between the small inner metallic head and the ultra-high molecularweight polyethylene (UHMWPE) socket. The UHMWPE socket is bonded to an outer stainless steel shell, and this outer shell articulates with the acetabulum. Various other authors have advocated use of bipolar prosthesis in posttraumatic conditions and avascular necrosis of femoral head. ${ }^{3-5}$ With success of bipolar prosthesis in fracture neck of femur, its indication was extended to various other hip pathologies like advanced osteoarthritis of hip, rheumatoid arthritis, avascular necrosis of femoral head or even cases with acetabular dysplasia, which were previously being treated by total hip arthroplasty. ${ }^{3}$ The unique design of bipolar prosthesis helped to reduce the shear stresses and decrease the incidence of protrusio acetabuli and stem loosening. ${ }^{4,5}$ The impact loads are better absorbed by the bipolar prosthesis, thus providing further protection for the acetabulum. ${ }^{2}$ Added advantage of greater stability and reduced likelihood of dislocation was attained with the bipolar hip prosthesis. ${ }^{2,6}$

Several authors have reported good to excellent short-term and intermediate-term results with the use of bipolar prosthesis for osteoarthritis (OA) of the hip, avascular necrosis (AVN) of the femoral head, rheumatoid arthritis (RA), ankylosing arthritis, tuberculosis (TB) of hip. ${ }^{7-9}$ However, mid to long-term follow-up demonstrated unacceptably high rates of complications like pain, migration of prosthesis, osteolysis, and the need for revision to total hip arthroplasty. ${ }^{10-13}$ The objective of this study was to analyze the long-term outcomes of Banaras Hindu University (BHU) bicentric bipolar hemiarthroplasty applied to these indications including the inner and outer bearing movements of the prosthesis.

\section{METHODOLOGY}

It was a longitudinal study conducted between March 2002 to March 2012, where 35 bipolar hemi-replacement arthroplasties were performed for the treatment of various non-traumatic hip pathologies causing hip OA secondary to healed TB hip, RA, AVN and Ankylosing arthritis of hip. Five patients lost to follow up during the period of time, hence remaining 30 were included in the study. All the operated patients had preoperative modified Harris hip score of less than 50. Patients with age less than 30 and more than 60 or have had previous hip surgery were excluded from the study.

A patented bipolar prosthesis by name "BHU bicentric bipolar prosthesis" designed by the second author was used for the study. First and second author were involved in the surgery and case management. Second author was involved from the beginning of the study hence had maintained all the records of the patients whereas first author was involved in the last three years of study.

It is a bipolar hip prosthesis with some design modification, compared to the conventional bipolar hip prosthesis. BHU bicentic bipolar prosthesis has passed through various stages of stem design and modifications, which were tried on cadaver bones. The final design was approved and national patent was obtained and has been used in this study after ethical approval from the institutional review committee (Figure 1).

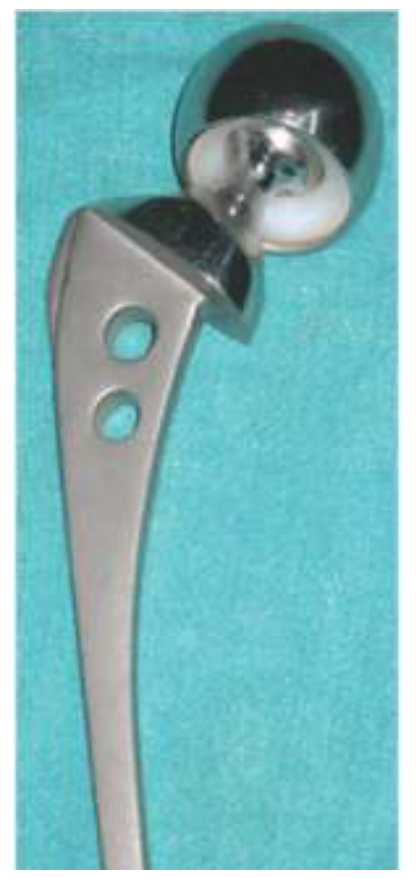

Figure 1 : BHU bicentric bipolar hip prosthesis

All the surgeries were performed by senior surgeons with patients under general anesthesia or spinal anesthesia, after taking written informed consent. Patients were positioned in lateral decubitus and Harding lateral approach was used. In all the cases uncemented type of hip hemi-replacement arthroplasty was performed. The postoperative protocol was to encourage the patients to perform quadriceps strengthening exercise from postoperative day 1 and partial weight bearing walking was allowed from $3^{\text {rd }}$ day after the operation and full weight bearing was allowed at 6 week from the date of operation. The patients were followed at 6 weeks, 3 months, 9 months, 12 months than 6 monthly for 4 years and then yearly till last follow up. At each follow up, radiological assessment of movement at the inner and outer bearing of prosthesis was done by plain anteroposterior radiograph of bilateral hip in neutral position and then in maximum abduction. Additionally, clinical assessment was done by self-administered modified Harris hip score based on pain, function, entry in public transportation, absence of deformity, range of motion, sitting crossed legged (Table 1). Grading of modified Harris hip score was as follows: 1. Poor: 0-69 2. Fair: 70-79 3. Good: 80-89 4. Excellent: 90-105. 
Table 1: Modified Harris hip Scoring System

\section{Pain}

None or ignores it

Slight, occasional, no compromise in activities

Mild pain, no effect on average activities, rarely moderate pain with unusual activity; may take aspirin

Moderate pain, tolerable but makes concessions to pain; some limitation of ordinary activity or work; may require occasional pain medicine stronger than aspirin Marked pain, serious limitation of activities Totally disabled, crippled, pain in bed, bedrid den

\section{FUNCTION}

LIMP

None

Slight

Moderate

Severe

SUPPORT

None

Cane for long walks

Cane most of the time

One crutch

Two canes

Two crutches

Not able to walk

ABILITY TO WALK

Indoors only

Bed and chair

Unlimited

Six blocks

Two or three blocks

STAIRS

Normally without using a railing

Normally using a railing

In any manner

Unable to do stairs

PUT ON SHOES AND SOCKS

With ease

With difficulty

Unable

\section{SITTING}

Comfortably in ordinary chair one hour

On a high chair for one-half hour

Unable to sit comfortably in any chair

3. Enter public transportation: Yes / No

5. ABSENCE OF DEFORMITY (All Yes $=4$; Less Than $4=0$ )

Less than $30^{\circ}$ fixed flexion contracture: Yes No

Less than $10^{\circ}$ fixed adduction:

Yes No

Less than $10^{\circ}$ fixed internal rotation: Yes No

Limb length discrepancy less than $3.2 \mathrm{~cm}$ : Yes No

\section{RANGE OF MOTION (*Normal)}

Total degree measurements, then check range to obtain score

Flexion $\left(* 140^{\circ}\right)$ : External rotation $\left(* 40^{\circ}\right)$ :

Abduction $\left(* 40^{\circ}\right)$ : Internal rotation $\left(* 40^{\circ}\right)$ :

Adduction $\left(* 40^{\circ}\right)$ :

\section{RANGE-OF-MOTION SCALE:}

$211^{\circ}-300^{\circ}$

$161^{\circ}-210^{\circ}$

$101^{\circ}-160^{\circ}$

$60-100^{\circ}$

$31^{\circ}-60^{\circ}$

$0^{\circ}-30^{\circ}$

5
4
3
2
1
0

7.

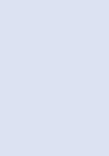

\section{Sitting Cross legged}

With ease

With difficulty

Can't

Total 


\section{RESULTS}

Out of 30 patients, 17 were males and 13 were females. Their age ranged from 30 to 60 years. Osteoarthritis of hip secondary to TB hip was present in 15 patients, 7 had RA, 2 had ankylosing spondylitis and 6 had AVN of hip. Radiological assessment of movement and fraction of it occurring at various components at each follow up are tabulated in table 2. At first follow up at 6 weeks, $75.82 \%$ of total prosthetic movement was occurring at inner bearing while only $24.18 \%$ of motion was occurring between the acetabulum and prosthesis. At 1 year follow-up $(n=21)$ the movement at the inter-prosthetic joint has steadily been above $70 \%$ of total motion while for next 7 years $(n=2)$ the movement at inter-prosthetic joint was around $70 \%$ of the total movement. While after 8 years follow-up, $(n=2)$ percentage of movement at inner bearing gradually increased and by 10 years $(n=1)$ all the movement was occurring between inter-prosthetic joint (Graph 1).

Patients based self-assessment was done by modified Harris hip score questionnaire at each follow up (Table 3), At 6 months follow up $(n=30) 14.28 \%$ patients had good outcome, $61.91 \%$ had fair outcome and $28.57 \%$ had poor outcome. While by 1 years $(n=21) 14.28 \%$ had excellent outcome, $7.14 \%$ had good outcome, $42.86 \%$ had fair outcome and $35.72 \%$ had poor outcome. By the end of 4.5 years $(n=7)$ all the patients had excellent outcome on modified Harris hip score (Graph 2).

Table 2: Abduction movement and fraction of it occurring at various components

\begin{tabular}{|cccccc|}
\hline Duration & $\begin{array}{c}\text { Total } \\
\text { [mean value in } \\
\text { degrees] }\end{array}$ & $\begin{array}{c}\text { Outer[mean value } \\
\text { in degrees] }\end{array}$ & Percentage & $\begin{array}{c}\text { Inner [mean value } \\
\text { in degrees] }\end{array}$ & Percentage \\
\hline $\begin{array}{c}6 \text { weeks } \\
(n=30)\end{array}$ & 20.43 & 4.94 & 24.18 & 15.49 & 75.82 \\
\hline $\begin{array}{c}3 \text { months } \\
(n=30)\end{array}$ & 23.21 & 6.21 & 26.76 & 17.00 & 73.24 \\
\hline $\begin{array}{c}6 \text { months } \\
(n=30)\end{array}$ & 23.16 & 6.42 & 27.72 & 16.74 & 72.28 \\
\hline $\begin{array}{l}9 \text { months } \\
(n=25)\end{array}$ & 20.32 & 5.67 & 27.90 & 14.65 & 72.10 \\
\hline $\begin{array}{l}1 \text { years } \\
(n=21)\end{array}$ & 22.14 & 6.14 & 27.73 & 16 & 72.27 \\
\hline $\begin{array}{l}11 / 2 \text { years } \\
(n=19)\end{array}$ & 21.32 & 6.82 & 31.99 & 14.5 & 68.01 \\
\hline $\begin{array}{l}2 \text { years } \\
(n=16)\end{array}$ & 22.4 & 7.84 & 35.00 & 14.56 & 65.00 \\
\hline $\begin{array}{l}21 / 2 \text { years } \\
(n=14)\end{array}$ & 19.82 & 6.1 & 30.78 & 13.72 & 69.22 \\
\hline $\begin{array}{l}3 \text { years } \\
(n=13)\end{array}$ & 22.42 & 7.43 & 33.14 & 14.99 & 66.86 \\
\hline $\begin{array}{l}31 / 2 \text { years } \\
(n=12)\end{array}$ & 24.6 & 7.65 & 31.10 & 16.95 & 68.90 \\
\hline $\begin{array}{l}4 \text { years } \\
(n=10)\end{array}$ & 25.5 & 7.54 & 29.57 & 17.96 & 70.43 \\
\hline $\begin{array}{c}1 / 1 / 2 \text { year } \\
(n=7)\end{array}$ & 24.86 & 8.2 & 32.98 & 16.66 & 67.02 \\
\hline $\begin{array}{l}5 \text { years } \\
(n=5)\end{array}$ & 25.45 & 7.45 & 29.27 & 18 & 70.73 \\
\hline $\begin{array}{l}6 \text { years } \\
(n=3)\end{array}$ & 25.86 & 7.24 & 27.99 & 18.62 & 72.01 \\
\hline $\begin{array}{l}7 \text { years } \\
(n=2)\end{array}$ & 25.54 & 7.20 & 28.19 & 18.34 & 71.80 \\
\hline
\end{tabular}

\begin{tabular}{|lccccc}
\hline $\begin{array}{l}8 \text { years } \\
(n=2)\end{array}$ & 30 & 4 & 13.33 & 26 & 86.66 \\
\hline $\begin{array}{l}9 \text { years } \\
(n=1)\end{array}$ & 30 & 2 & 6.66 & 28 & 93.33 \\
\hline $\begin{array}{l}10 \text { years } \\
(n=1)\end{array}$ & 30 & 0 & 0 & 30 & 100 \\
\hline
\end{tabular}

Table 3: Analysis of Modified Harris Hip Score

\begin{tabular}{lcccc}
\hline & Excellent & Good & Fair & Poor \\
\hline 6 week $(n=30)$ & 0 & 9.52 & 28.57 & 61.91 \\
\hline 3 months $(n=30)$ & 0 & 9.52 & 57.14 & 33.34 \\
\hline 6 months $(n=30)$ & 0 & 14.28 & 61.91 & 28.57 \\
\hline 9 months $(n=25)$ & 11.76 & 17.64 & 35.3 & 35.3 \\
\hline 1 year $(n=21)$ & 14.28 & 7.14 & 42.86 & 35.72 \\
\hline $1 \frac{1}{2}$ years $(n=19)$ & 14.28 & 7.14 & 42.86 & 35.72 \\
\hline 2 years $(n=16)$ & 33.33 & 25 & 16.67 & 25 \\
\hline $2 \frac{1}{2}$ years $(n=14)$ & 50 & 0 & 25 & 25 \\
\hline 3 years $(n=13)$ & 50.0 & 12.5 & 12.5 & 25 \\
\hline $3 \frac{1}{2}$ years $(n=12)$ & 75 & 0 & 25 & 0 \\
\hline 4 years $(n=10)$ & 75 & 0 & 25 & 0 \\
\hline $4 \frac{1}{2}$ years $(n=7)$ & 100 & 0 & 0 & 0 \\
\hline 5 years $(n=5)$ & 100 & 0 & 0 & 0 \\
\hline 6 years $(n=3)$ & 100 & 0 & 0 & 0 \\
\hline 7 years $(n=2)$ & 100 & 0 & 0 & 0 \\
\hline 8 years $(n=2)$ & 100 & 0 & 0 & 0 \\
\hline 9 years $(n=1)$ & 100 & 0 & 0 & 0 \\
\hline 10 years $(n=1)$ & 100 & 0 & 0 & 0 \\
\hline
\end{tabular}

\section{DISCUSSION}

Total hip arthroplasty is already an established and standard modality of treatment for severe OA of hip secondary to rheumatoid arthritis, avascular necrosis of femoral head and is being performed all over the world. Although the early and intermediate outcomes were very successful and promising with longer follow up surgeons are tackling complications like acetabular component loosening, instability, dislocation and difficulty in revision. Relatively simple and gratifying procedure of bipolar hip arthroplasty could be a good and cheaper alternative in both aged and younger patients with hip OA. Almost $80 \%$ of patients showed good to excellent results after bipolar hip arthroplasty in study conducted by Dudani et al. Bateman in his series of 760 degenerative hip has shown good results with improvement of Harris hip score from 51 to 87 after bipolar hip arthroplasty. ${ }^{15}, 7$ McConville et al. found bipolar hip arthroplasty as viable option against THA, in their series of 100 consecutive patients of degenerative arthritis of hip. ${ }^{8}$ At an average follow-up of 65.7 months Pandit et al. noticed $93-96 \%$ hips had good to excellent results after bipolar hip arthroplasty, which was comparable to our study where at end of 4.5 years all 7 patients had excellent results. ${ }^{16}$ 
We propose changes in the design of BHU bicentric bipolar prosthesis as mentioned by Rai et al. for the prolonged preservation of movement at inter-prosthetic joint, and good to excellent modified Harris hip score in majority of patients in this series. ${ }^{17,}{ }^{18}$ Modification of seating angle between the stem and the collar has allowed preservation of the calcar by quarter to $1 \mathrm{~cm}$ after implantation of the prosthesis. Due to low seating angle in conventional bipolar (Bateman type), the calcar has to be sacrificed during the surgery and hence on weight bearing the prosthesis tends to sink if cement is not used. ${ }^{17,}{ }^{18}$ The ultra-high molecular weight polyethylene (UHMWPE) lining has a beveled margin (Figure 3). Thus, reduces wear and debris formation at extremes of the movement. ${ }^{17,18}$ The neck of the prosthesis has been made trapezoidal like the Charnley type neck and the cup has been modified in a staggering fashion to decrease neck cup impingement. This modification in design has grossly improved movement at the inner articulation and avoided the neck cup impingement, thereby increasing the life of the bipolar prosthesis. UHMWPE wear in a bipolar prosthesis is $0.7 \mathrm{~mm} /$ year. A $22 \mathrm{~mm}$ Charnley head diameter has been used in the BHU bicentric bipolar prosthesis, so that thicker UHMWPE can be provided in outer bearing, thereby increasing the survivorship of the prosthesis. ${ }^{17,}{ }^{18}$ Moreover, smaller sized head further provides increased movement at the inner bearing for a longer time, adding longevity to the prosthesis. BHU bicentric bipolar prosthesis is available in 37-55 $\mathrm{mm}$ head sizes in $1 \mathrm{~mm}$ increments, which provides appropriate head size for replacement and subsequently prevents early failure of the prosthesis, by avoiding Hertzian contact stress. $^{17,18}$ The BHU bicentric bipolar prosthesis allows crossed legged sitting and squatting without limiting patient range of movement at the hip (Figure 4).
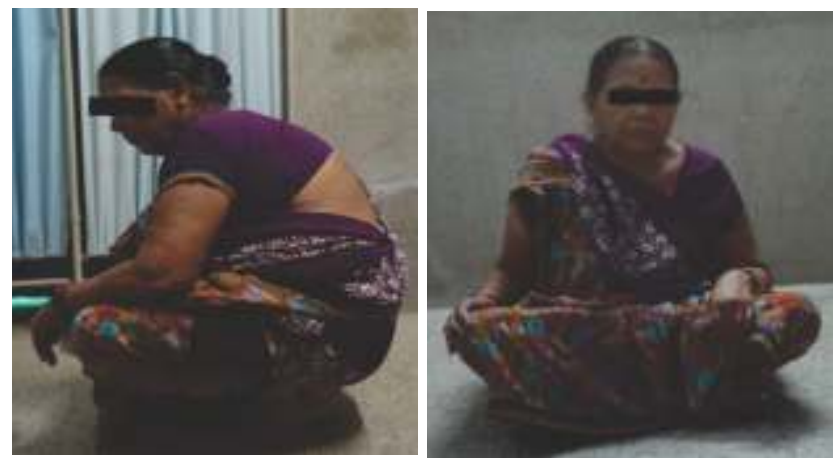

Figure 4 : Eight year follow up : Patient squatting and sitting crossed legged

Bipolar hip arthroplasty has been used as a treatment for AVN of femoral head. ${ }^{13,19,20,21}$ Chan et al. found no statistical difference in clinical results, thigh pain, groin pain, osteolysis, dislocation, and revision rate while comparing bipolar hip arthroplasty with THA for hip osteonecrosis in the same patient. ${ }^{22}$ In contrast to our results, Hiroshi et al. showed inferior results of bipolar hip arthroplasty in osteonecrosis of femoral head. ${ }^{23}$ They had $42 \%$ of radiographic failure, $42 \%$ patients had groin pain and $25 \%$ hip required revision surgery. Hence, they no longer used bipolar hip arthroplasty for AVN of hip. Similarly, Ito et al. ${ }^{24}$ demonstrated that the average Harris hip score improved from 46 to 86 in patients treated with bipolar hemiarthroplsty for AVN hip, but at final follow-up of average 11.4 years, 20 $(42 \%)$ hips had radiographic failures, 12 (25\%) hips were revised and groin symptoms were present in 20 (42\%) hips. Hence they no longer recommend bipolar prosthesis for the treatment of osteonecrosis of femoral head.

Vazquez-vela et al. noticed in all patients with protusio and thin medial wall there was no increase in protusio, rather in majority of patients there was significant thickening of the medical acetabular wall. ${ }^{9}$ In none of the patients, bone graft was used. Incidence of ectopic para-articular bone formation following total hip arthroplasty is variable in literature. However, functional impairment due to this occurs in $3-10 \%$ cases of THA. ${ }^{25,26}$ Incidence of this complication is remarkably less in cases of bipolar hip arthroplasty since this is a relatively simple procedure where minimal capsular exposure is required and acetabular preparation is either not required or is minimal. Bhan et al. in their study of bipolar hip arthroplasty in ankylosing spondylitis concluded that bipolar arthroplasty gives excellent results in OA hip secondary to $A S$, since it is technically easy, has lower risk of initiating heterotopic ossification and provides excellent functional recovery. ${ }^{27}$

In a study by Rai et al. where they used BHU bipolar prosthesis in treatment of intra-capsular fracture neck of femur they noticed gradual increase in movement at outer bearing, which was $80.51 \%$ at last follow-up. ${ }^{17}$ Similarly, the movement at the inner bearing gradually decreased from a mean of $7.53(31.4 \%)$ to $4.5(19.49 \%)$. They concluded that there was a slight loss of movement at the inner bearing over the months on subsequent follow up as compared to the first follow up, whereas this difference was not statistically significant.

\section{CONCLUSION}

The BHU bicentric bipolar prosthesis has been shown to be a good option for non-traumatic hip disorders, as it is associated with better clinical outcomes.

\section{RECOMMENDATION}

It may be a viable alternative to the costly total hip replacement arthroplasty for the poor Indian subcontinent patients.

\section{LIMITATION OF THE STUDY}

The findings of this study should be interpreted in line with the following limitations. First our sample size was small with only one of the patient having 10 years follow-up. Second, 5 patients were lost to follow-up.

\section{ACKNOWLEDGMENT}

We would like to acknowledge all our patients for their support and participation in the study.

\section{CONFLICT OF INTEREST}

The authors have read the manuscript and declare that there are no conflicts of interest in relation to the article. 


\section{REFERENCES}

1. Bateman JE. Single assembly total hip prosthesis: Preliminary report. Orthop Digest. 1974; 2: 15.

2. Giliberty RP. Bipolar endoprosthesis minimizes protrusio acetabuli, loose stems. Orthop Rev. 1985; 14: 27.

3. Bateman JE. Experience with a multiple bearing implant in hip joint reconstruction. Orthop Trans. 1981; 5:421.

4. Devas M, Hinves B. Prevention of acetabular erosion after hemiarthroplasty for fractured neck of femur. J Bone Joint Surg (Br). 1983; 65: 548.

5. Scott RD. Use of a bipolar prosthesis with bone grafting in acetabular reconstruction. Contemp Orthop. 1984; 9: 35.

6. Drinker $H$, Murray WR. The universal proximal femoral endoprosthesis. J Bone Joint Surg (Am). 1979; 61: 116.

7. Bateman JE, Berenji AR, Bayne O, Greyson ND. Long term results of bipolar arthroplasty in osteoarthiritis of hip. Clin Orthop. 1990; 251:54.

8. McConville OR, Bowman AJ Jr, Kilfoyle RM, McConville JF, Mayo RA. Bipolar hip arthroplasty in degenerative arthritis of the hip. Clin Orthop. 1990; 251: 67

9. Vazquez-vela G, Vazquez-vela E, Dobarganes FG. The Bateman bipolar prosthesis in osteoarthritis and rheumatoid arthritis - a review of 400 cases. Clin Orthop. 1990; 251: 82.

10. Pellegrini VD Jr, Heiges BA, Bixler B, Lehman EB, Davis CM 3rd. Minimum ten-year results of primary bipolar hip arthroplasty for degenerative arthritis of the hip. J Bone Joint Surg Am. 2006; 88: 1817.

11. Lee SB, Sugano N, Nakata K, Matsui M, Ohzono K. Comparison between bipolar hemiarthroplasty and THA for osteonecrosis of the femoral head. Clin Orthop. 2004; 424:161.

12. Yun AG, Martin S, Zurakowski D, Scott R. Bipolar hemiarthroplasty in juvenile rheumatoid arthritis: long-term survivorship and outcomes. J Arthroplasty. 2002; 17: 978.

13. Cabanela ME. Bipolar versus total hip arthroplasty for avascular necrosis of the femoral head. A comparison Clin Orthop. 1990; 261, 59.
14. Bochner RM, Pellicci PM, Lyden JP. Bipolar hemiarthroplasty for fracture of the femoral neck. Clinical review with special emphasis on prosthetic motion. J Bone Joint Surg Am. 1988; 70: 1001.

15. Dudani BG, Thawrani D, Chikale S. Outcome measures of bipolar hip arthroplasty for atraumatic hip disorders- A preliminary report. Indian J Orthop. 2005; 39: 212.

16. Pandit R. Bipolar femoral head arthroplasty in osteoarthritis. A prospective study with a minimum 5-year follow-up period. J Arthroplasty. 1996; 11: 560.

17. Rai AK, Agarwal $R$, Singh $S$, Ratan R. The BHU bicentric bipolar prosthesis in fracture neck femur in active elderly. J Trauma Manag Outcomes. 2008; 2: 7.

18. Rai A K, Singh S, Kumaraswamy V, Khare G N, Yadav V, Agarwal R. Bicentric bipolar hip prosthesis: A radiological study of movement at the interprosthetic joint. Indian J Orthop. 2011; 45: 508.

19. Lachiewicz PF, Desman SM. The bipolar endoprosthesis in avascular necrosis of the femoral head. J Arthroplasty. 1988; 3:131.

20. Floren $M$, Lester D. Outcomes of total hip arthroplasty and contralat-eral bipolar hemiarthroplasty: a case series. J Bone Joint Surg (Am). 2003; 85-A(3): 523.

21. International Bipolar News. The Uses of the Bipolar Cup in Trauma and Degenerative Pathologies. Meeting Report 11-12th April 1997; Foggia, Italy.

22. Chan $Y$, Shih C. Bipolar versus total hip arthroplasty for hip osteonecrosis in the same patient. Clin Orthop. 2000; 379:169.

23. Hiroshi I, Matsuno T, Kaneda K. Bipolar hip arthroplasty for osteonecrosis of the femoral head - a 7 to 18 years follow up. Clin Orthop. 2000; $374: 201$.

24. Ito $H$, Matsuno $T$, Kaneda K. Bipolar hemiarthroplasty for osteonecrosis of the femoral head. A 7- to 18-year followup. Clin Orthop Relat Res. 2000 May; (374): 201.

25. Rosendahl S, Krogh CJ, Norgaard M. Paraarticular ossification following hip replacement. Acta Orthop Scand. 1977; 58: 400.

26. Ling RSM. Complications of total hip replacement. Edinburgh: Churchill Livingstone. 1984.

27. BhanS, Malhotra R. Bipolar hip arthroplasty in ankylosing spondylitis. Arch Orthop Trauma Surg. 1996; 115(2): 94. 